ÉGYPTE

monde arabe

\section{Égypte/Monde arabe}

3| 1990

Médiateur et métaphores 2

\title{
Crise du Golfe, annexe III : Un acte de pillage (III)
}

Al-Tawhid, Rabi'Awwal 1411 hég.

\section{Chaykh Muhammad 'Alî 'Abd al-Rahîm}

\section{(2) OpenEdition}

Journals

Édition électronique

URL : https://journals.openedition.org/ema/1883

DOI : 10.4000/ema.1883

ISSN : 2090-7273

Éditeur

CEDEJ - Centre d'études et de documentation économiques juridiques et sociales

Édition imprimée

Date de publication : 30 septembre 1990

Pagination : 230-233

ISSN : 1110-5097

Référence électronique

Chaykh Muhammad 'Alî 'Abd al-Rahîm, "Crise du Golfe, annexe III : Un acte de pillage (III) », Égypte/ Monde arabe [En ligne], 3 | 1990, mis en ligne le 08 juillet 2008, consulté le 07 juillet 2022. URL : http:// journals.openedition.org/ema/1883; DOI : https://doi.org/10.4000/ema.1883

Ce document a été généré automatiquement le 7 juillet 2022

Tous droits réservés 


\title{
Crise du Golfe, annexe III : Un acte de pillage (III)
}

\author{
Al-Tawhid, Rabi'Awwal 1411 hég. \\ Chaykh Muhammad ‘Alî ‘Abd al-Rahîm
}

1 Le monde arabe a connu des époques que l'histoire a qualifiées de fastes ou de néfastes. Ainsi les Tatars, venus d'Asie centrale, donnèrent-ils le coup de grâce, en 656 hég., au califat abbasside déjà affaibli du fait de la décadence des califes et de leur abandon de la religion. Extrêmement éprouvante pour les musulmans, cette chute entraîna à tous les niveaux des pertes considérables: les Tatars pillèrent l'Irak, massacrant la population et ruinant le pays : plus d'un demi-million de citoyens périrent dans la seule ville de Bagdad.

2 Parvenus à l'ouest de l'Irak, en route vers (le territoire que couvre actuellement) la Syrie, ils se heurtèrent aux troupes du sultan égyptien qui régnait alors sur cette région. Les combats sanglants auxquels prirent part les ulémas musulmans, le chaykh Ibn Taymiyya à leur tête - que Dieu l'entoure de sa grâce - se soldèrent par une défaite cuisante des Tatars,

3 L'histoire n'offre guère d'exemples plus ignobles que les crimes perpétrés par les Tatars à Bagdad. Mais les musulmans, ayant recouvré leurs forces, leur imposèrent un revers impitoyable. En Syrie, les Tatars, affaiblis, s'abstinrent d'actes de pillage et finirent par se convertir à l'islam.

4 Les Croisades, qui durèrent deux cents ans, favorisaient tantôt les musulmans en Égypte et en Syrie, tantôt les Croisés d'Europe, qui parvinrent à occuper certaines villes syriennes. Ces derniers avaient pour premier souci d'arracher Jérusalem des mains des musulmans. D'ardents combats opposèrent les deux parties, s'étendant jusqu'à Damiette et à Mansura où le chef des Croisés fut fait prisonnier. Saladin - que Dieu l'entoure de sa paix - leur fit subir une défaite cuisante au VI siècle de l'Hégire (XII ${ }^{\mathrm{e}}$ siècle après J.-C.).

5 En dépit de la haine implacable que se vouaient alors musulmans et chrétiens, les Croisés n'ont accompli aucun des actes de vandalisme que l'armée de Saddam Hussein 
ne cesse de perpétrer actuellement contre le Koweït. Ses soldats ont pillé banques, magasins et maisons, rafflant ce qu'ils y trouvaient de plus précieux, sans oublier le vol de voitures enlevées à leurs passagers et l'acheminement, à destination de Bagdad, de camions chargés de denrées alimentaires et de divers articles dérobés. Les Koweïtiens se sont dispersés dans les rues puis ont cherché refuge dans le désert, privés de ressources, affamés et assoiffés. L'invasion visait à faire main basse sur les puits de pétrole frontaliers, notamment ceux d'Al-Barqan qui produisent plus de deux millions de barils de brut par jour et ont permis au Koweït d'occuper une place privilégiée parmi les exportateurs, avec une exportation de cinq millions de barils par jour \{sic\}. Mais si tel était l'objectif de l'invasion, pourquoi braquer les canons des tanks sur les maisons, notamment dans le quartier des notables et des émirs, maisons qu'ils ont détruit de fond en comble? Un millier de tanks ont envahi le Koweït, ce petit pays incapable d'affronter une telle force. Devant les envahisseurs, les citoyens ont été contraints de fuir dans le désert en laissant tout. Y a-t-il crime plus ignoble à l'égard d'un peuple pacifique? La religion islamique condamne la tyrannie et ordonne de mettre fin aux actes du tyran, conformément à ces paroles du Prophète - que la grâce de Dieu lui soit rendue : « Soutiens ton frère, qu'il se montre injuste ou pâtisse d'une injustice. » À ceux qui lui demandaient : « Messager de Dieu, nous le soutiendrons s'il pâtit d'une injustice, mais comment le soutenir s'il se montre injuste? » «C'est en l'empêchant de l'être que vous le soutiendrez.»

6 Les plus importants des champs pétroliers d'Arabie Saoudite se situant à quelque quarante kilomètres seulement de ceux du Koweït, le tyran avait décidé de s'emparer de toute la région. Le Koweït étant tombé devant mille tanks, il fallait prendre les mesures susceptibles d'empêcher l'Irak de s'emparer des puits saoudiens.

7 Il importe à ce stade de regarder en arrière : l'on notera que l'appel du roi Fahd aux troupes américaines n'est rien d'autre que l'exécution d'un traité (cf. ci-après) conclu par son père, le roi Abd al-'Aziz - que Dieu l'ait en sa sainte grâce - avec une compagnie américaine dont le siège se trouvait à Dhahran, à $500 \mathrm{~km}$ à l'est de Ryad et à $800 \mathrm{~km}$ des frontières septentrionales, dont le pétrole fait l'objet du litige. Il n'y a donc rien d'étonnant dans un tel appel. [...]

Arrêtons-nous un moment pour secouer les esprits intoxiqués par une propagande pernicieuse destinée à salir les Saoudiens, propagande selon laquelle le roi Fahd a permis aux Américains de profaner les Lieux saints. Pure diffamation, car une distance de $1800 \mathrm{~km}$ séparent les zones pétrolifères frontalières de la Sainte Mecque.

\section{Statut des traités et accords conclus avec les polythéistes et les non musulmans}

9 L'islam interdit la violation des traités et accords. Le premier traité passé entre musulmans et infidèles fut signé par le Messager de Dieu - que Dieu l'ait en sa protection - en l'an 6 hég., pendant la 'Umra (petit pèlerinage) de Hudaybiyya. Il prévoyait le retour du Messager de Dieu à Médine cette année-là, puis sa venue à la 'Umra l'année suivante, outre d'autres stipulations rapportées dans la sunna et la sîra du Prophète. Ce dernier respecta les clauses du traité, le dénonçant seulement quand il fut transgressé par les Quraychites et, avec l'appui de Dieu, conquit la Mecque en l'an 8 hég. 
Le messager de Dieu - que Sa paix soit sur lui - a conclu un autre traité avec les juifs de Bari Qurayza afin qu'ils empêchent les tribus adverses de passer par la région dans laquelle ils étaient installés et où le fossé n'avait pas été creusé. Et lorsque les païens assiégèrent la cité pendant quatre semaines, échangeant des flèches avec les musulmans, les Bani Qurayza trahirent leur engagement et faillirent permettre aux tribus de pénétrer dans la ville. Mais Dieu fit souffler sur eux un vent violent et glacial qui les dispersa. Battus, les Quraychites et les partis se replièrent. Les Bani Qurayza furent ensuite châtiés par le Prophète, qui les chassa de la ville.

11 J'ai voulu démontrer par là qu'il est possible de conclure des traités avec des païens et des non-musulmans et que les traités et accords doivent être respectés.

\section{Accord conclu entre le Royaume et la compagnie américaine}

Pendant le règne du roi 'Abd al-Aziz al-Sa'ud - que Dieu ait son âme - un accord fut conclu entre le Royaume saoudien et la plus importante des compagnies américaines. Signé en 1353 hég. (1933), cet accord prévoyait d'octroyer à la compagnie un droit de prospection du pétrole sur une concession de 440000 miles carrés. Cette compagnie fusionna ensuite avec d'autres, donnant naissance à l'Aramco (compagnie araboaméricaine) qui regroupait les actionnaires suivants :

1. Compagnie Standard oil of Cafifomia, $30 \%$ des actions.

2. Compagnie Texas. $30 \%$.

3. Compagnie New Jersey. $30 \%$.

4. Compagnie Scony Facom oil, $10 \%$.

La production, qui avait débuté en 1359 hég.(1939) avec la découverte du champ de Dhahran à Damman, dans le Golfe arabique, puis d'autres gisements, ne dépassait pas la valeur de 3 millions de $€$. Elle s'éleva par la suite - en 1958 très précisément - à environ 150 millions de $€$. La production cessa avec le le déclenchement de la deuxième Guerre mondiale, se limitant à l'approvisionnement des flottes alliées dans l'Océan Indien.

En 1946, la guerre ayant pris fin, la compagnie Aramco accrut sa production, qu'elle exportait par cargos transitant par le canal de Suez. Le pétrole saoudien fut donc affecté par la fermeture du canal lors de la crise de 1956. Mais son exportation s'est poursuivie sans interruption depuis la création de l'oléoduc rattachant Dhahran au port libanais de Saïda et n'a pris fin qu'avec le déclenchement de la guerre civile au Liban.

La prospérité matérielle dont jouissait l'Arabie Saoudite permit à la compagnie Aramco de créer une ligne ferroviaire longue de $650 \mathrm{~km}$ reliant Ryad au port de Damman, sur le Golfe.

Le Chaykh Abd 'Allah Al-Sulayman, alors ministre des Finances du Royaume d'Arabie Saoudite, a signé le 4 safar hég. (29 mai 1933) à Djedda, avec M. Hamilton, représentant de la compagnie, un accord autorisant celle-ci à effectuer des travaux de prospection et des investissements. En voici les clauses principales:

1. La concession est valable pour une durée de 60 ans (durée qui sera prorogée par la suite) à compter de l'année 1933, durée à l'expiration de laquelle la propriété de toutes les installations construites par la compagnie dans le Royaume reviendra au gouvernement 
saoudien. (Cette clause fut ensuite amendée en raison de la nationalisation qui intervînt en faveur des autorités locales.)

2. En vertu des conditions posées par le roi Abd al-Aziz, les deux parties se partageront les bénéfices à égalité. De même, s'il s'avère à l'avenir que toute compagnie pétrolière, dans quelque pays que ce soit, perçoit plus de la moitié des bénéfices, la différence revient de plein droit au gouvernement saoudien.

3. La compagnie n'est pas autorisée à construire des églises : tout bâtiment porteur d'une croix est interdit. (J'ai visité personnellement la région de Dhahran, notamment son aéroport et ses installations, et j'ai pu voir une base imposante, sorte d'enclave de l'Amérique, qui comporte des logements - dont 60 \% sont consacrés aux Saoudiens - pour les ouvriers et les ingénieurs.)

4. En cas de guerre, l'Amérique est chargée de défendre les installations de la compagnie si elles sont l'objet d'une agression.

17 Tel est globalement le contenu de l'accord conclu entre le Royaume et la compagnie américaine. Donc, au cas où, parallèlement à l'invasion du Koweït, l'Irak menacerait le Royaume de s'emparer des puits de pétrole frontaliers, particulièrement riches, et que le roi Fahd soit contraint de mettre en application les termes de l'accord conclu du vivant de son père - que Dieu ait son âme - doit-on considérer sa démarche comme une trahison des Lieux saints, sachant notamment que plus de $1800 \mathrm{~km}$ séparent la région où sont concentrées les troupes américaines et la sainte Mecque?

18 Si je vous apporte ces informations, que beaucoup perdent de vue, c'est parce que le Tout-Puissant m'a accordé l'honneur de travailler pendant longtemps dans le Royaume, sous le règne successif des rois Abd al-Aziz, Sa'ud, Fayçal et Khalid - que Dieu ait leur âmes. Ils ont tous suivi le chemin tracé par leur père; c'est grâce à leurs efforts que le pays a connu la prospérité et que, grâce à leurs dons généreux, les Lieux saints de l'islam ont été rénovés.

Nous implorons Dieu de faire triompher la vérité et de vaincre l'erreur, car les tyrans connaîtront bientôt leur destin. Dieu est le guide.

\section{AUTEUR}

\section{CHAYKH MUHAMMAD ‘ALÎ ‘ABD AL-RAHÎM}

Chef de l'Association al-Tawhid 